\title{
Barriers to solving environmental problems caused by building constructions in Nigeria: Trudgills's framework
}

\author{
Ahmad Abdullah $^{1 \star}$, Ibrahim Faruk Gaya ${ }^{1}$ and Zarma Ali Wakil ${ }^{2}$ \\ ${ }^{1}$ Department of Geography, Federal University of Kashere, Nigeria. \\ ${ }^{2}$ Nigeria Building and Road Research Institute, Nort-east zonal office, Gombe, Nigeria. \\ ${ }^{*}$ Corresponding author. Email: yawaji1330@gmail.com
}

Copyright (c) 2021 Abdullah et al. This article remains permanently open access under the terms of the Creative Commons Attribution License 4.0, which permits unrestricted use, distribution, and reproduction in any medium, provided the original work is properly cited.

Received 27th February, 2021; Accepted 13th March, 2021

\begin{abstract}
Our environment has been compromised through unwise and unplanned use of land, air, and water exacerbated by population increase, science and technology so much that some areas in Nigeria no longer support life as it ought to. Continuous impacting negatively on the environment to afford us the luxury building construction can afford, eventually leads us to short term and long term economic and environmental grief. At various forum, conferences and literatures, scientists have raised this concern. Not only have concerns been raised, solutions and recommendations were proffered, yet the problems linger. This work adopted Trudgill's a range of possible barriers to a better environment occasioned by many facets of human activities on earth, ranked the barriers according to Likert's scale to determine which of these barriers hinders solving environmental problems caused by building constructions. Data from building and construction practitioners were collected using a questionnaire on masons, architects, land surveyors, structural engineers and clients/contractors through semi-structured. The result indicates that lack of political will and political ideology to implement the solutions proffered and the recommendations made in various researches was ranked as the first or major barrier to solving environmental problem caused by building constructions followed by economic insufficiencies. The third barrier according to the study was technology related barrier. The study recommends green building initiative by government and all stake holders in the construction sector.
\end{abstract}

Keywords: Barrier, building, constructions, environment, Nigeria, Trudgill.

\section{INTRODUCTION}

It is not no longer contentious that environment, our only life support system has been compromised through degradation to a level where some areas on the earth surface do not give the utilities as they ought to. Some other places have been rendered useless unless some forms of remediation measures are employed. The farming communities in Northern Nigeria for example have to resort to the use of biological and chemical fertilizers in order to feed the ever growing population. Yet still, the levels of degradation in some areas have become so devastating that it poses great danger to man and his property if he continues to live there.

Unwise and unplanned use of the environmental components (land, air and water) exacerbated by population increase, science and technology has made man to impact negatively on the environment. Land is the most fundamental natural resource, because it provides nearly all the food we use today. It also provides space on which we live (Cutter and Renwick, 1999). Increase in population means more land is required to feed the people and because it is in finite supply, competing uses are restricted. Where more land is unavailable, people implore the use of technology and chemicals to increase food supply. On non-agricultural use, more land is required for residential uses or for variety of other uses like road, airports, rail lines, reservoirs, sports, security, and education, corporate and commercial buildings to say the least. In the quest to provide the aforementioned, air and water, the other two vital environmental components are equally affected negatively. 
There have been cultural shifts on the existence of man on earth. Notable among these are hunting and gathering, agricultural revolution, industrial revolution and counting. Prior to hunting and gathering culture, the environment provides a perfect setting comprising of a balanced supply of sunlight, pure air, water, carbon dioxide and land. That means there was equilibrium between man's use of the environmental resources and what mature provides in the environment. Whenever there was a shortfall in any of the components, the environment through its internal mechanism, remedies the situation through renewal. These resources helped in the development of plants, animals and man (Anil and Arnab, 2005). Of the cultural shifts mentioned above, industrial revolution was the most devastating in degrading the environment.

Industrial revolution started in the 1700s in Britain and later in U.S. in 1800. This culture increased the average per capita energy consumption of man in a process of increased production, trade and distribution of goods and services. The production of goods, trade and its distribution, are processes among others that increase $\mathrm{CO}_{2}$ in the atmosphere, increased consumption of nonrenewable energy, destroy wild life and take over large portion of land. The processes also require small, medium, and large construction exercises. When you build a factory, there is a need for building a trade centre. The distribution of goods and services require the construction of roads, and/or rail lines. All over the world, every year about 6million hectares of land disappear for construction of houses, roads, mines, factories e.t.c. (Cutter and Renwick, 1999). Many analysts believe that this cultural change in how man sees his relationship to nature and each other is a major cause of today's environmental degradation (Eziashi, 2007).

Some environmentalist realized that since the advent of industrial revolution, the number of people have increased eight folds, industrial production rose by more than 200 times in the 21st century, habitats have been cleared by more than 6 million $\mathrm{km}^{2}$, sediment load in rivers have risen 3-8 folds, air pollution have more than doubled the presence of methane in the atmosphere, increase of $27 \%$ of $\mathrm{CO}_{2}$ concentration in the air couple with doubled the contamination of water bodies by natural and anthropogenic sources (Park, 1997).

The contribution of building sector in environmental problem is worthy of note. Its damaging effects can be seen from three phases. These are during construction, during the life span upon which the building is put to use and during its demolition to pave way to other uses or for renovation. It is evident in the sense that if a parcel of land is used for construction, then not only does this satisfy the wants upon which it was put, but it also means, that runoff from that land will contain certain by-products of the construction sites (litters, sediments and chemicals) in form of non- point water pollution. Furthermore, the use of a parcel of land for one purpose has implications for other purposes. To construct a stadium, a large parking space is required; a good network of roads to link residential areas to the facility; water, soil, and other natural resources need to be sourced from other areas. Same goes with the construction of corporate buildings, housing estates, airports and dams. Apart from occupying space, a lot of habitat is being destroyed. To a larger extent, building requires precious natural resources: soil, stones, gravels, forest wood, fiber, rubber, water, marble, and much more. Gardner (2003) asserted that building construction consumes $40 \%$ of the world's raw stone, grave and sand, $25 \%$ of the virgin wood, $40 \%$ of energy and $16 \%$ of water annually. Building construction also uses significant amount of energy in all the three phases mentioned above. Of concern is the negative impact that is being done to the environment as a result of energy expended. In all the phases of building life span mentioned earlier, energy is required and essentially there a corresponding release of wastes. According to Levin (1997) in the USA, construction is responsible for $40 \%$ of atmospheric pollution, $20 \%$ of water effluents, and $13 \%$ of other releases. During transportation of materials to building sites, dust, and other emissions including some toxic substances such as nitrogen and sulphur oxides found their way into the environment. Other harmful substances, such as chlorofluorocarbons are used in insulation, air conditioning, refrigerating plant and firefighting systems and have seriously depleted the ozone layer (Clough, 1994, Langford et al, 1999).

Many scholars have proffered recommendations to curb the excesses made by building construction on the environment, yet the problems linger and continue to remain a major concern to world leaders and the academia. Simon and Samuel (2015) recommended collaboration between government and stakeholders in building construction to come up with special legislations, codes or standards relating to sustainable construction practices. Lifts (2019) wrote that buildings play a huge part in the economic development of a city...business owners and investors are becoming increasingly aware of how our natural resources are being gobbled up by the industry along with the alarming rate in which pollutants and wastes are being generated. He therefore borrows a leaf from US government and emphasize on the need for green construction during policy deliberations.

Armed with this information, we must recognize that continuous impacting negatively on the environment to afford us the luxury building construction can afford, eventually leads us to short term and long term economic and environmental grief. We will have to allow some parts of the environment we have damaged to heal; help restore severely damage areas and protect remaining wild areas from any form of destructive development. However, this easier said than done. This is because there is significant diversity of barriers to the adoption of whatever method there is to heal, restore and protect the environment impacted by building sector. These barriers as put forward by Trudgill in 1990 are agreement, knowledge, technology, 
economic, political and social (AKTEPS). They highlight a range of possible barriers to a better environment occasioned by many facets of human activities on earth. A growing number of researchers have implemented the AKTESP framework in their investigations of barriers to achieving a better environment: examples include public resistance to solar energy (Haw et al, 2009), the implementation of cumulative effects assessment (Piper, 2001), the conservation of cultural landscapes (Selman, 2004), as well as the development of large-scale wind energy on a regional scale (Richards et al., 2012). The widespread use of the AKTESP Framework illustrates its applicability to diverse environmental challenges. This work ranked the barriers according to Likert's scale to determine which of these barriers hinders solving environmental problems caused by building constructions. The barriers are not however rigid, but are used as a framework for investigation and analysis on Nigeria's building construction sector.

\section{Aim and objective of the study}

The aim of this work is to examine a range of barriers to solving environmental problems occasioned by building construction sector in Nigeria using a Trudgill's framework for a better environment. Essentially, the study will achieve that through:

a. Identifying major environment problems caused by building constructions in Nigeria.

b. Investigating building clients, contractors and practitioners' perception on the barriers to solving environmental problems caused by building construction in Nigeria using the Trudgill's framework.

c. To recommend ways that will help in addressing barriers to a better environment caused by building construction.

It is authors believe that once a problem is identified and accepted by those who are faced with that problem, an agenda for action will be set in motion to tackle it.

\section{LITERATURE REVIEW}

Environmental problem can be perceived from two perspectives according to Trudgill (1990). He opined that the first definition can be made through the general approach in terms of a situation in the environment which falls short of people's aspirations, wants and goals. The second has to do with conflict of interest among people. A situation where some people find it damaging and unacceptable, while others see it as beneficial, acceptable or unimportant. An environment problem is not only one which detracts from the resource base of the planet and its life support system but also one where there is a situation which some people see as detracting from the resource base and its life support system but where others deny that such a detraction exists or even where there is a general acceptance of a problem but it is seen as too complex, unwieldy or difficult to do anything about it (Trudgill, 1990). Similarly, Eziashi 2010 sees environmental problem as a situation where the resource base of the planet which support life is damaged in such a way as to decrease the quality of the resource, thus damaging life which it support, and which involves disagreement in that only some people involved recognize that the situation is unacceptable while others deny its significance, or where there is a situation which most people recognize as unacceptable but where progress to a resolution is impeded by some other barriers.

Any development project plan to improve the quality of life has some built-in positive and negative impacts (Kaur and Arora, 2012). It is expected that construction damages the fragile environment because of adverse impacts of construction. These impacts include resource depletion, biological diversity losses due to raw material extraction, landfill problems due to waste generation, lower worker productivity, adverse human health due to poor indoor air quality, global warming, acid rain, and smog due to emissions generated by building product manufacture and transport that consumes energy (Lippiatt, 1999). According to new research by construction blogBinhow, the construction sector contributes to $23 \%$ of air pollution, $50 \%$ of climate change, $40 \%$ of drinking water pollution and $50 \%$ of landfill waste. In a separate research, the construction industry accounts for $40 \%$ of energy usage, with estimation that by 2030 , emissions from commercial buildings will grow by $1.8 \%$ (U.S. green building council, 2019). Construction sector is ever-expanding as cities and towns are growing. This sector uses over 400 million tons of construction material every year, and many of these materials have negative impact on environment. The extraction, use and waste of materials add to the problem. Chemicals on site, excessive use of energy also create problems. (Prem, 2019). However, the impact of construction on environmentis mostly negative these include change in the lay of the land, increase in particulate pollution, use of excess energy and water, filling up of landfills with construction and demolition debris, effluents, gas, and oil that pollutes the land in transporting construction materials.

Environmental impacts of building are categorized into safeguards subjects: ecosystem impacts, natural resources impacts and public impacts (Li et al., 2010; Change et al., 2011; Zolfagharian et al., 2012). According to Kaur and Arors, 2012, negative environment impacts that affects ecosystem in building constructions include solid waste, noise, dust, toxic generation, air pollution, water pollution, bad odour, climate change, and hazardous emissions. Waste water is generated from construction activities, sewage, commercial activities and other sources. Natural resources are impacted by building constructions as they are used during the construction 
phase and building lifespan. The resources used include energy, land, materials, and water. Construction sector is responsible for consuming high volume of natural resources and generating a high amount of pollution as a result of energy consumption during extraction and transportation of raw materials (Li et al., 2010; Morel et al., 2001). In terms of public impact, most construction projects are located in densely populated areas. Li et al. (2010) observed that people who live at or close to construction sites are prone to harmful effects on their health because dust, vibration and noise due to certain construction activities such as excavation, and pile driving. Both renovation and destruction of buildings results in huge amount of non- recyclable waste. Such wastes include concrete, glass, wood, metals, plastics bricks and asphalt (Lifts, 2010). According to US EPA, there were $170+$ million tons of debris generated by both demolition and construction of buildings in 2003. Sixty-one percent $(61 \%)$ of the wastes mentioned above were generated by non-residential buildings.

Climate change scientists believe that the Earth is rapidly getting warmer and that human activity is playing a significant role in accelerating this process. The biggest way in which construction firms are doing this is by contributing to carbon dioxide emissions. Carbon dioxide is a gaseous product of burning fossil fuels like gas and diesel. This gas gets trapped in our atmosphere, creating a "greenhouse effect" that warms the Earth over a long period of time. Given that, every construction project results in the emission of carbon dioxide, methane, and other waste products that pollute the air, it should therefore be believed that air pollution from building constructions contributes to global climate change. The most harmful aspect of construction in terms of contributing to climate change is the operation of heavy machinery in mining projects that extract raw materials from the Earth for use in construction projects. The global cement industry contributes approximately $5 \%$ of global carbon dioxide emissions. Applications of fuel and electricity are also major contributors - fossil fuels are used to extract and transport minerals, to process materials, and even to power tools on construction sites.

The building and construction sectors are key sectors for sustainable development. While the building industry generates 5 to $15 \%$ of the global GDP, the built environment is responsible for one-third of the total final energy use and half of worldwide electricity consumption, as well as one-third of global carbon emissions. According to the latest IPCC report, the energy use and related emissions from buildings can double or possibly even triple until 2050 as a result of several key trends, including growth in population, relocation to urban areas, changes in family size, rising levels of affluence, and behavioral changes (Emami et al., 2016).

Guidance provided in EMAS regulation was used to initially identify generic environmental impacts of building construction as follows: (1) emissions to air, (2) releases to water, (3) avoidance, recycling, reuse, transportation and disposal of solid and other wastes, particularly hazardous wastes, (4) use and contamination of land, (5) use of natural resources and raw materials (including energy), (6) local issues (noise, vibration, odour, dust, visual appearance, etc.), (7) transport issues, (8) risks of environmental accidents and impacts arising, or likely to arise, as consequences of incidents, accidents and potential emergency situations and (9) effects on biodiversity.

\section{METHODOLOGY}

Data collected for this study were obtained from two sources, building practitioners and the literatures. Data from building and construction practitioners were collected using a questionnaire on masons, architects, land surveyors, structural engineers and clients/contractors through semi-structured interview. The questionnaires were divided into three sections- administration (name of respondents, age, gender, qualification, name of association), impacts of building construction on the environment and perception of respondents on the relative importance of the impacts of barriers to solving environment problem caused by constructions among other questions. Information from this source formed our primary source data.

The other source of the data was obtained from federal and state governments building regulations and edicts. This information was required to determine governments' conscious effort to safeguard the environment from the negative impacts of building construction. Books, journals, the internet and newspapers were studied for more information on the impacts of building construction on the environment, the barrier to solution to a better environment, and what other authors wrote on the topic under review. Information from this source formed our secondary source of data.

\section{Sample selection}

The subjects of the study were initially 180 building practitioners comprising of masons, architects, land surveyors, structural engineers, and clients/contractors. In the study design, only respondents who acquired diploma and above as their educational qualification and have registered with their professional bodies were selected for inclusion in data analysis. This was done to ensure that respondents are aware and have a fair knowledge of environmental components and what natural and anthropogenic actions impact the environment. Moreover, a brief explanation was done to respondents to acquaint them with the Trudgill's framework as barriers to solving environmental problem. At the end of the interview, 96 responses were found suitable for the research analysis. 
Table 1. Qualification of respondents.

\begin{tabular}{lccc}
\hline Qualification & Frequency & Relative frequency & Percentage \\
\hline Diploma & 15 & 0.1 & 10 \\
Degree & 45 & 0.5 & 50 \\
Msc & 36 & 0.4 & 40 \\
PhD & 0 & 0.0 & 0 \\
Total & 96 & 1.0 & 100 \\
\hline
\end{tabular}

Table 2. Respondents' unions and associations.

\begin{tabular}{lccc}
\hline Association & Frequency & Relative frequency & Percentage \\
\hline NIA & 26 & 0.3 & 30 \\
NSE & 13 & 0.1 & 10 \\
NIQS & 21 & 0.2 & 20 \\
NAET & 14 & 0.2 & 20 \\
NAOB & 12 & 0.1 & 10 \\
NICE & 10 & 0.1 & 10 \\
Total & 96 & 1.0 & 100 \\
\hline
\end{tabular}

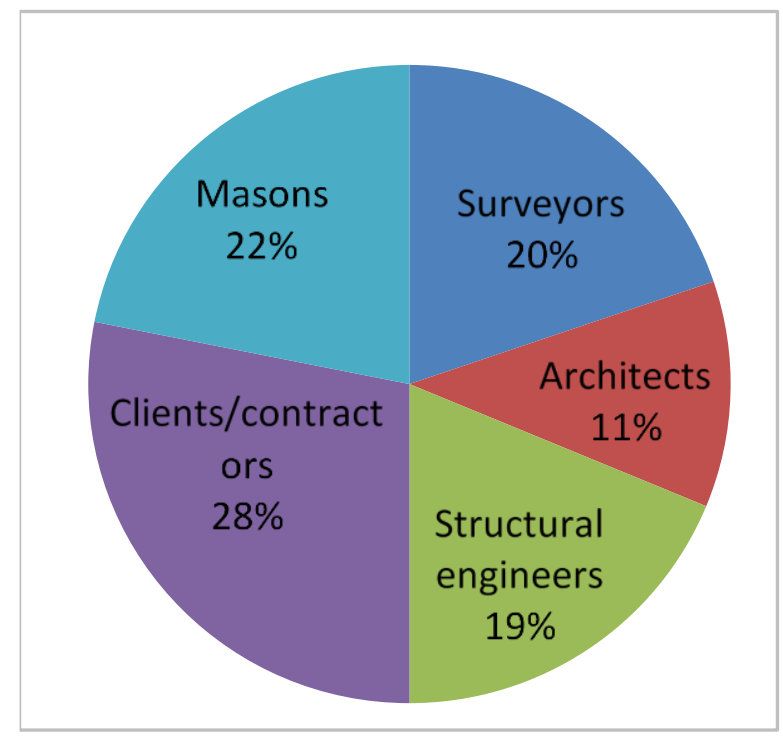

Figure 1. Occupation of respondents.

These include responses from surveyors 20, structural engineers 24, architects 11, clients/contractors 30 and masons 20. The remaining responses were relegated because they were found to have fall short of criteria for selection mentioned above.

The survey was conducted in November 2020 over a two weeks period simultaneously from 9:00 to 11:00 am daily across the country. The month of November was chosen because rainfall across the country in November is very unlikely, and the time of the day was to coincide with the time when building practitioners will be found on sites of constructions.

\section{RESULTS}

Table 1 shows the educational qualification of respondents. A minimum of a diploma is required to qualify as a respondent. Statistics shows that $10 \%$ of the respondents hold diploma, 50\% Bsc holders, and $40 \%$ were holders of Master's Degree in building related fields of study.

Figure 1 further classifies the respondents according to their specialization in building construction. $20 \%$ of them are surveyors and $10 \%$ architects. Structural engineers, contractors and masons constitute 20, 30 and 20\% respectively.

Table 2 shows respondents' unions and associations. The Table 2 shows that $30 \%$ of the respondents are members of National Institute of Architects. $20 \%$ of the respondents are certified members of National Institute of Quantity Surveyors and Nigerian Association of Engineering Technicians respectively, other associations to which the respondents are members are NSE 10\%, National Association of Builders and Nigerian Institute of Civil Engineers with $10 \%$ of the members each.

The result of the objective of the study to seek to investigate the barriers to solving environmental problems occasioned by building construction is summarized in Table 3.

\section{DISCUSSION}

Building constructions account for generic environmental problems and natural resource consumption at a rate faster than it can be replenished within a short time. It also affects biodiversity of which some are affected to the level 
Table 3. Relative importance index ranking.

\begin{tabular}{|c|c|c|c|c|c|c|c|c|}
\hline \multirow{2}{*}{ Barriers } & \multicolumn{5}{|c|}{ Frequency of occurrence observed from 96 respondents } & \multirow{2}{*}{$\%$ score } & \multirow{2}{*}{ RII } & \multirow{2}{*}{ Ranking } \\
\hline & 5 & 4 & 3 & 2 & 1 & & & \\
\hline Agreement & 33 & 15 & 6 & 27 & 15 & 312 & 3.25 & 4th \\
\hline Knowledge & 33 & 15 & 6 & 06 & 12 & 277 & 2.88 & 6th \\
\hline Technology & 39 & 09 & 21 & 24 & 03 & 345 & 3.59 & 3rd \\
\hline Economy & 33 & 30 & 09 & 12 & 12 & 348 & 3.63 & 2nd \\
\hline Social & 24 & 15 & 27 & 12 & 18 & 303 & 3.15 & 5 th \\
\hline Political & 66 & 18 & 03 & 03 & 06 & 423 & 4.40 & $1 \mathrm{st}$ \\
\hline
\end{tabular}

of extinction. These problems though can be caused by natural and other anthropogenic activities, the contribution of building construction is becoming alarming and has began to draw the attention of policy makers and the academia. Solutions have been proffered, for instance, Enshassi et al. (2014) opined that enhancing the awareness of construction participants with regard to impacts of construction in the environment and search about alternative methods for construction to mitigate the adverse impacts of construction on the environment. And measures have been taken by governments and development partners to curb the excesses of building construction in our environment, yet the problems lingers. Research findings as shown in Table 3 indicate that lack of political will and political ideology to implement the solutions proffered and the recommendations made in various researches was ranked as the first or major barrier to solving environmental problem caused by building constructions. This result is similar to the findings of Mercer (2016) that the vast majority of participants (71\%) believed that "political" issues were affecting the rate of wind energy development in the Newfoundland and Labrador. The second barrier in this work as identified by the respondents indicates that economic insufficiency, economic denial, inappropriate use of economy and economic corruption are the barriers to solve the environmental problem occasioned by building construction. This finding was corroborated with the work of Mercer (2016) which also observed that majority of participants $(65 \%)$ believed that "economic" issues were affecting the rate of wind energy development in the province, though there are slight differences in themes. Application of inappropriate technology and complacency was ranked by the respondents as the barrier. They opined that though technology was available and affordable in Nigeria but its application where and when necessary has been a problem. They also indicate that where there is the technology, complacency sets in until things get worse. They also observed that inappropriate application of technology and use of substandard materials to check environmental problems hinder the success of all solutions put forward to solve Nigeria's environmental problems. Fourth, fifth and sixth barriers to solving environmental problem according to the research are knowledge, inadequacy, rejection and lack of sensitization; social value system and lack of patriotism and agreement on whether the problems exist.

\section{Conclusion and Recommendations}

Having identified the major barriers to tackling the problems, reducing energy use in buildings is one of the most important ways to reduce human's overall environmental impact, there is therefore a need to stress ideological belief in going green by people. Electorates must insist that political parties must bring green policies into their manifesto and existing regimes must be made to evolve and show greater political will and commitments in a greener direction. Furthermore, budgetary allocations to environmental concerns must be increased substantially; bills must be sponsored by members of national assembly to push for a legislation that will compel building practitioners to evolve the trending green building initiatives; the existing building regulations must be reviewed to tally with current green building codes.

If the problem of economic insufficiency is to be tackled, government must ensure prudent use of public funds and reduce corruption to the barest minimum. To solve technology barrier, government and private organizations must encourage financial support to technological innovations; learn from past experiences and from what trends in other climes in terms of building construction. This can help Nigerians to cut down the energy usage, save money, and make a big impact on the environment.

\section{CONFLICT OF INTEREST}

The authors declare that they have no conflict of interest.

\section{REFERENCES}

Clough, R. (1994). Environmental impact of building construction. In: proceedings of first international conference: building and the environment, BRE Watford, UK.

Cutter, S. L., \& Renwick, W. H. (1999). Exploitation, conservation, preservation: a geographic perspective on natural resource use (No. Ed. 3). John Wiley \& Sons, Inc., New York.

Edoka A. I., Richard, A. J., Bamidele O. A., \& Abdulkadir, B. A. 
(2013). An assessment of environmental impact of building construction projects. Civil and Engineering Research. 3(1), 93-104.

Emami, N., Marteinsson, B., \& Heinonen, J. (2016). Environmental impact assessment of a School building in Iceland using LCA-including the effect of long-distance transport of materials. Buildings, 6(4), 46.

Enshassi, A., Kochendoerfer, B., \& Rizq, E. (2015). An evaluation of environmental impacts of construction projects. Revista Ingeniería de Construcción, 29(3), 234-254.

Eziashi, A. C. (2008). Conceptual developments in manenvironmental relationship. Lecture notes on environmental management, Unijos Printing Press, Jos, Nigeria.

Gardner, G. (2003). State of the world 2003: A Worldwatch Institute report on progress toward a sustainable society.

Kumar A. and Arnab A. (2005). Environmental studies. New Age International (p) limited publishers, New Delhi.

Langford, D. A., Zhang, X. Q., Macleod, I., Dimitrijevic, B., \& Maver, T. (1999). Design and managing for sustainable buildings in the UK'. Profitable Partnering in Construction Procurement, E\&F Spon, London, UK.

Levin, H. (1997). Systematic evaluation and assessment of building environmental performance (SEABEP). In: proceedings of second international conference, building and the environment. June, Paris. Pp. 3-10.

Mercer, N. M. J. (2016). Barriers to renewable energy development in Newfoundland and Labrador: a case study of wind energy applying the 'AKTESP' framework for analysis (Doctoral dissertation, Memorial University of Newfoundland).
Miller, G. T. Jr (1993). Environmental science: sustaining the earth. Belmont California-Wadsworth publishing company. Pp. 21-31.

Richards, G., Noble, B., \& Belcher, K. (2012). Barriers to renewable energy development: A case study of large-scale wind energy in Saskatchewan, Canada. Energy Policy, 42, 691-698.

Simon O. A., \& Samuel K. A. (2014). Impacts of construction activities on the environment: The case of Ghana. Journal of Construction Project Management and Innovation, 4(s1), 934948.

Sonya S. (2017). How does construction impact the environment? Retrieved from https://gocontractor.com/blog/how-does-construction-impactthe-environment/.

Tyler (2017). The environmental impacts of construction projects and the next steps forward form the industry. Retrieved from https://esub.com/blog/environmental-impacts-of-constructionprojects/.

Urge-Worsatz, D. (2007). Climate change mitigation in the building sector: 4th assessment report of the IPCC. 